\title{
NEW DEVELOPMENTS IN GAS CLEANING TECHNOLOGY FOR IRONMAKING TOWARDS A CLEANER FUTURE*
}

\author{
Andreas Steinwandter ${ }^{1}$ \\ Martin Smith 2 \\ Tomotsugu Masuda ${ }^{3}$
}

\begin{abstract}
The demand for increasing energy efficiency and $\mathrm{CO} 2$ reduction is one of the global megatrends of our time. Although the steel industry suffers from a volatile economic environment, the steel plants are interested to find opportunities for sustainable cost reduction and put efforts into healthy solutions for the environmental. Integrated steel plants are trying to cut electrical power and energy costs as these are among the biggest cost factors that can be influenced and taking all the advantages they can. For the integrated iron and steel making route the interaction of waste energy utilization along with process energy demand, natural and metallurgical gases, steam and heating systems as well as power generation has to be considered. Potential energy sources, such as sinter plant, basic oxygen furnace (BOF) cooling stack or reheating furnaces are considered in order to elaborate an integrated energy concept. Especially electric power generation is an attractive option for steel plant operators since it can easily be connected to the existing power grid of the steel plant. When direct local use of waste heat is limited, the best option is to convert it to mechanical/electrical power with a Rankine Cycle. A stand-alone system, compact design with minimum operational costs in order to fit into the existing steel plant layout, are the main requirements of such units. The objective of this paper is to demonstrate economic feasible opportunities for energy recovery for sinter cooler and basic oxygen furnace with focus on electric power generation via ORC modules taking at the same time advantages of $\mathrm{CO} 2$ reduction by utilizing waste heat from the process. Furthermore typical arrangements and layouts of such solutions as well as basic economic calculations will be presented in the paper.

Keywords: Sinter Cooler, Basic Oxygen Furnace, Waste Heat Recovery, CO2 emissions reduction, Energy Efficiency, ORC modules, electric power generation.
\end{abstract}

Primetals Technologies / Austria.

Primetals Technologies / United Kingdom.

Mitsubishi Hitachi Power Systems/ Japan. 


\section{INTRODUCTION}

This article focuses on gas-cleaning options that truly show how a cleaner future is being implemented for our customers in the iron-industry.

Established and well proven solutions for the wet gas cleaning of blast furnace gas have been subject to replacement with dry gas cleaning technologies over the past 15 to 20 years mostly due to the limitation in water consumption. This impulses led to the development of more efficient wet dedusting systems and also to the increasing implementation of fully dry dedusting systems as well as the development of efficient coarse dust separators such as cyclones. This cyclones have higher separation degrees than common dustcatchers allow higher dust recirculation rates in the upstream processes (i.e. sinter plant).

The reduced pressure loss and higher top gas temperatures offer an additional advantage for the dry dedusting system when it comes down to the installation of a top gas recovery turbine to further increase the energy yield and boost the economic feasibility of the proposed technology.

\section{MATERIAL AND METHODS}

As emissions regulations are getting stricter also for sinter plants, catalytic technologies for reducing nitrous oxides (NOx) are getting more widespread in the iron- and steel industry. Primetals Technologies and MHPS (Mitsubishi Hitachi Power Systems, Ltd.) are offering the complete package combining a deep understanding of the sinter production process and the know-how of designing well proven innovative catalysts to ensure that the emission regulations are safely met with tailored solutions to minimize the operation costs of the gas cleaning plant.

\section{RESULTS AND DISCUSSION}

\subsection{Top gas conditioning}

The top gas temperatures from the blast furnace can vary strongly due to several processes within the blast furnace, such as slips, hangers, raw material moisture and characteristics and operation philosophy of the blast furnace operators.

Unlike wet systems the dry dedusting technology is rather sensitive to the top gas temperature. Even suitable high temperature resistant textile filtration media, such as P84@ or glass fiber felts are restricted to a maximum temperature of 200 to $250{ }^{\circ} \mathrm{C}$ in continuous operation. The filter bags can withstand for a short time also temperatures up to $280^{\circ} \mathrm{C}$ but it will affect negatively the lifetime of the filter bag. On the lower end the minimum temperature to operate the baghouse filter is strongly dependant on the dew point of the top gas and on the dust composition, as it may lead to clogged filter bags.

To handle low top gas temperature Primetals developed a burner system upstream the bag filters to maintain the top gas temperature over the minimum requirements for a safe operation. It therefore ensures a long filter bag lifetime and eliminates further any problems with the dust discharge in the dustcatcher / cyclone and minimizes the formation of build-ups in the gas ducts upstream the gas cleaning facilities. The burners can be operated for instance with coke oven gas or natural gas and with compressed air or mixtures with oxygen. A series of temperature and pressure transmitter and a fully automated control system ensures the top gas 
temperatures to stay over the fixed, minimum temperature. The system is designed for continuous operation to overcome also longer periods (i.e. during winter) with a maximum temperature increase of the top gas of up to $40 \mathrm{~K}$ and can compensate the failure of one burner. A state of the art burner control ensure the highest availability, fast response time and operational safety of the burner system in the top gas flow with a very low air/fuel ratio to minimize the oxygen intake into the blast furnace gas. The burners show a very stable behaviour and stay in operation during fast pressure changes in the blast furnace system (i.e. closing of bleeder valves, hanging blast furnace,...). To further increase the operational safety every individual burner can be equipped with one control unit, thus allowing a fully redundant operation of the top gas heating system.

In case the measured gas temperature in the BF head and in the off-takes falls below a threshold, the heating system is put into operation. After the start-up procedure is finished the burner control station will maintain the predefined set-point temperature until the temperature in the top is stable above the set-point and the additional burner system is no longer required to maintain the top gas temperature.

Slips within the blast furnace can generate a very serious threat to the filter bags, as these events may happen very fast and don't allow long reaction time. Primetals foresees a two-stage cooling concept, where stage one directs the water spray into the inlet of the off-takes and ensures a dense mist of fine droplets and efficient cooling of high temperature gas. The cooling stage is activated by fast acting valves and control mechanism whenever the temperature in all or only in one off-take rises above a defined first threshold. A second cooling stage is installed right upstream the filter vessels and can be seen as emergency cooling with twin-fluid nozzles in case the temperature peak slipped through the first cooling stage and at the temperature at the filter inlet rises close to the maximum allowable temperature for the filter bags. While the first cooling stage can be designed as a continuous cooling system in case of a special blast furnace operation philosophy the second stage is considered a truly emergency cooling system with an intermittent operation of less than 1 hour.

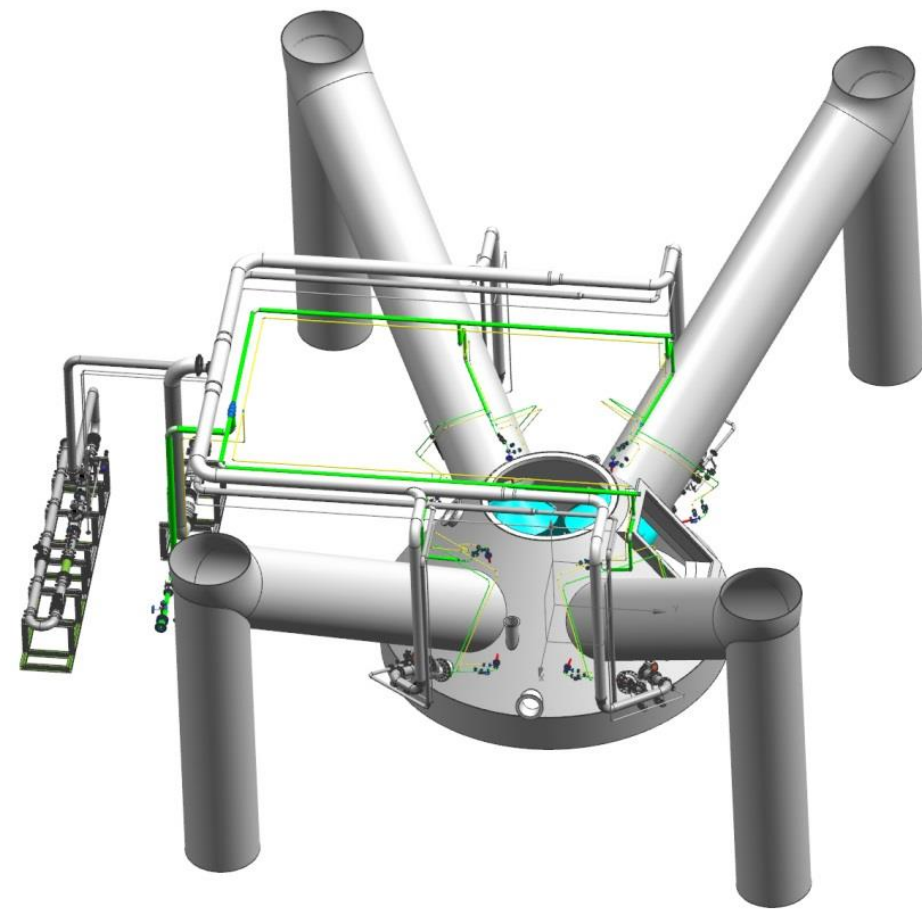

Figure 1. 3D screenshot of the top gas conditioning unit with the valve stands in the front 


\subsection{Dust pre-separation with Cyclone}

In place of the widespread dustcatchers which operate with a very simple dust separation principle, the development in the past years was directed to the installation of a cyclone separator. The installation of a cyclone leads to a considerably higher dust separation degree of 80 to $85 \%$ and therefore to a noticeable reduction of the amount of dust or sludge to be treated in the second gas cleaning stage. Furthermore the cyclone can be controlled and adjusted to achieve a very sharp separation of zinc in the dust, as zinc is volatized within the hot zones of the blast furnaces and condenses in the colder zones forming the fine fraction of the blast furnace dust with lower particle diameter and lower particle density. The dust, collected in the cyclone, shows very low zinc content and high amount of carbon and iron and can therefore be easily recycled to the sinter plant reducing the risk of creating build-ups in the blast furnace.

The entrance can be designed as a conventional tangential entry or as triple entrance (Fig. 2) with an optimized support of the downcomer in the center of gravity of the cyclone. An internal refractory lining was applied to the cyclone to reduce wear. The lining thickness was altered in certain areas according to the potential for wear, for example, a thicker lining was used in the tangential inlets due to the relatively high dust-laden gas velocity in this area.

The cyclone contains the dust collected approximately in one day in its hopper and the discharge sequence follows an automated procedure which is started by the operator. The filling level of the cyclone is monitored in various levels in the hopper and in the lock vessel to obtain reliable information about the discharge progress. The dust-flow control valve moves to a set position to ensure an acceptable flow of dust to the pug mill. The dust is humidified in a pug mill and loaded onto truck or wagons to be reused in other process steps of the integrated mill. As such, the design offers a most environmentally friendly solution for the removal of dust from the cyclone itself. 


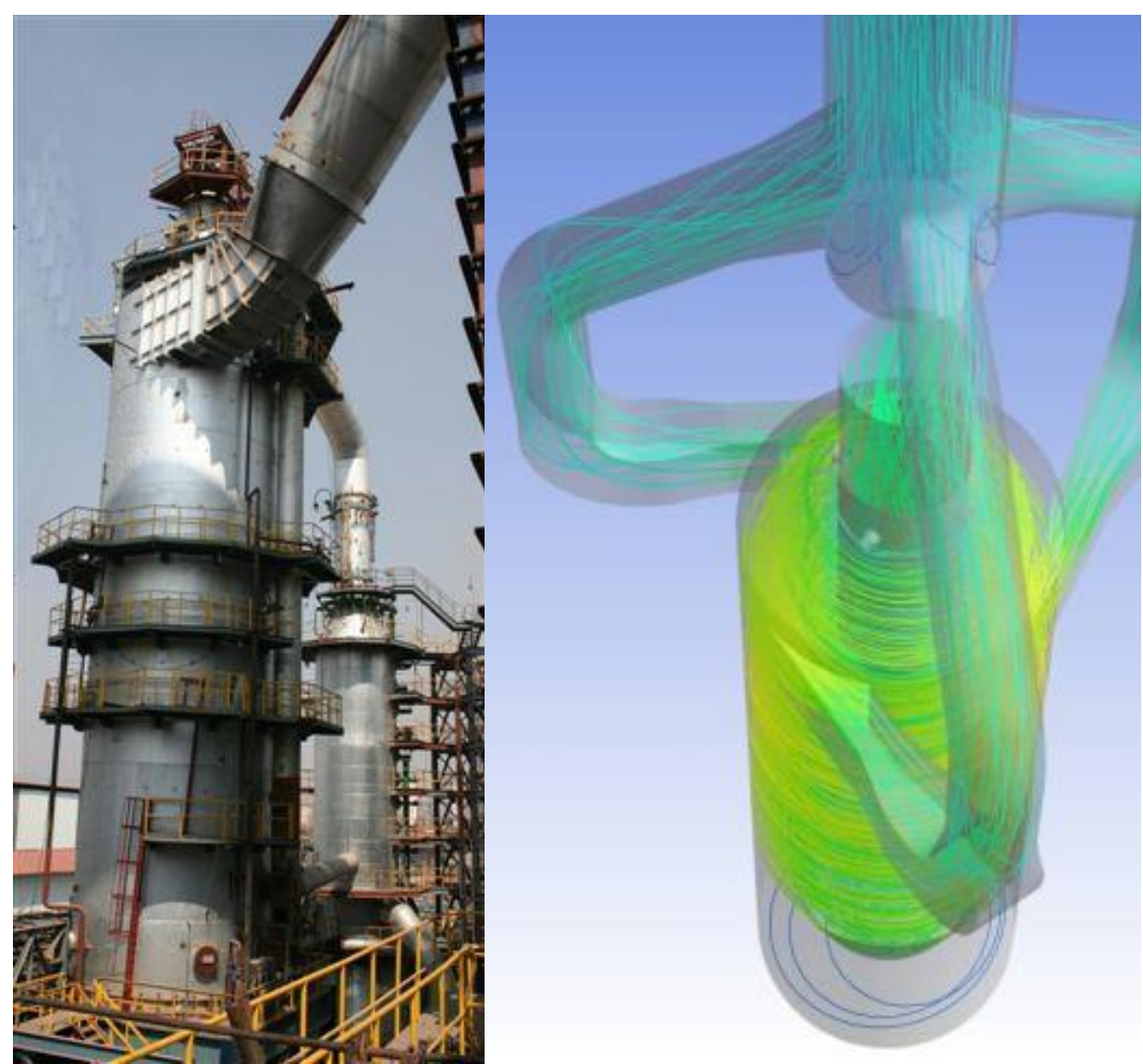

Figure 2. View on cyclone with single entry (left) and triple entry (right)

\subsection{Pulse Jet Filter}

The second stage of the gas cleaning can be either performed with a wet scrubber or in a dry dedusting stage. The dry dedusting plant consists of various independent, pressure resistant filter modules which are equipped with up to $10 \mathrm{~m}$ long filter bags made of glass fibre scrim and a e-PTFE-membrane to ensure lowest clean gas emissions in an acidic gas environment and with strongly fluctuating gas temperatures. Emphasis has to be put an equal gas distribution between the filter vessels and also within the filters. The filter bags are cleaned with pulse jets of pressurized nitrogen instead of compressed air, thus avoiding any risk of creating an explosive atmosphere in the filter. The fast actuating valves allow opening times of less than $150 \mathrm{~ms}$ and reduce the nitrogen consumption to a minimum and an additional compressor for the blast furnace gas is not required. This ensures a safe operation with highest availability without any risk of corrosion. Each vessel is monitored with triboelectric dust sensor to track the performance of the filter cleaning and to detect without delay possible filter bag damages. 
Table 1. Technical data Pulse Jet Filter

\begin{tabular}{|c|c|}
\hline Item & Parameter \\
\hline Amount of filter vessel & 4 \\
\hline Length filter bag & $8000 \mathrm{~mm}$ \\
\hline $\begin{array}{l}\text { Top gas flow } \\
\text { Nominal } \\
\text { Maximum }\end{array}$ & $\begin{array}{l}360000 \mathrm{Nm}^{3} / \mathrm{h} \\
400000 \mathrm{Nm}^{3} / \mathrm{h}\end{array}$ \\
\hline Minimum operation Temperature & $100^{\circ} \mathrm{C}$ \\
\hline Maximum operation temperature & $\begin{array}{l}\text { Continuous: } 250{ }^{\circ} \mathrm{C} \\
\text { Peak: } 280{ }^{\circ} \mathrm{C}\end{array}$ \\
\hline $\begin{array}{l}\text { Maximum design pressure for } \\
\text { operation }\end{array}$ & $2,5 \operatorname{bar}(g)$ \\
\hline Filter bag cleaning & Online / Offline \\
\hline Filter cleaning media & Compressed nitrogen \\
\hline Dust concentration inlet & $7 \mathrm{~g} / \mathrm{Nm}^{3}$ \\
\hline Dust concentration outlet & $<3 \mathrm{mg} / \mathrm{Nm}^{3}$ \\
\hline
\end{tabular}

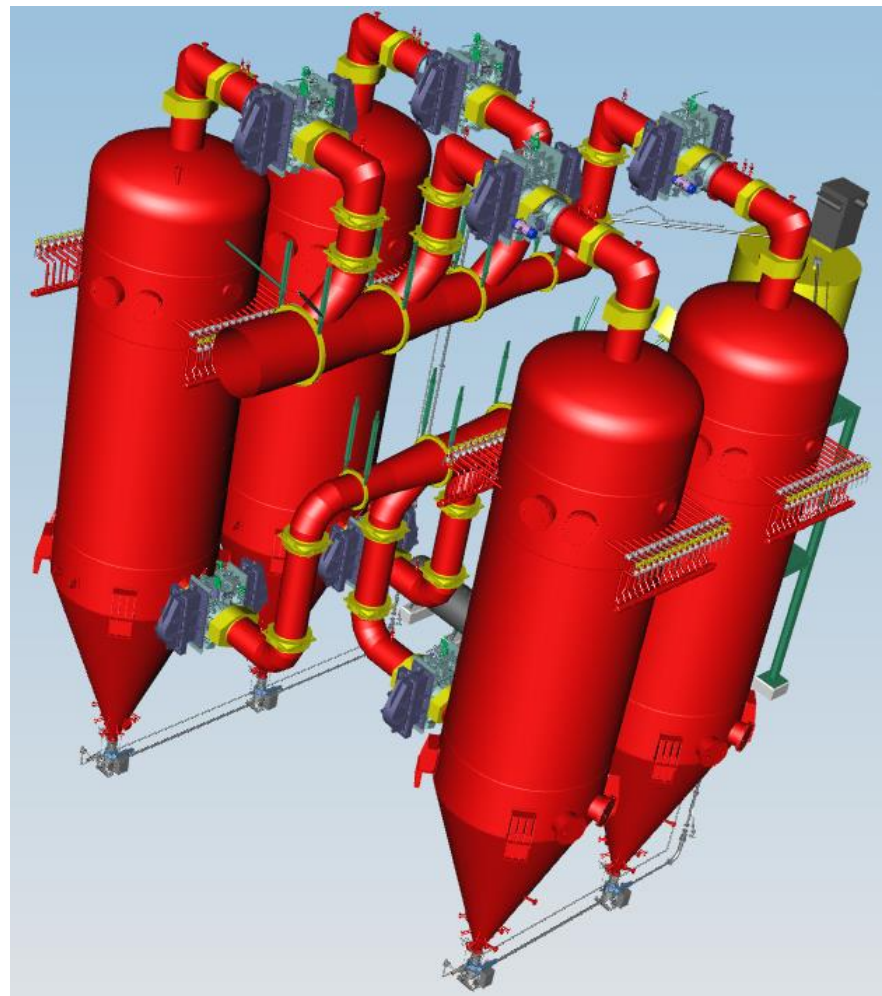

Figure 3. 3D screenshot of the pulse jet filter unit seen from the clean gas side.

The fine dust passing the first stage and entering the pulse jet filter has completely different properties and composition, as it shows due to the sharp separation in the cyclone high concentration of zinc, chlorine and alkaline compounds. A sufficient process temperature is recommended for a safe operation of the filter plant and the dust transport. Therefore the ducts starting with the cyclone outlet and the filter vessels itself are fully thermally insulated.

The plant is designed to allow blast furnace operation with full capacity even if one filter vessel might be out of operation due to maintenance or during offline cleaning. A set of goggle valves at the in- and outlet ensures safe maintenance within the filter vessel. Due to the advanced top gas conditioning unit the fine dedusting plant can be 
operated with much higher air to cloth ratios than other dry dedusting plants [1] thus reducing drastically the footprint of the installation.

The dust can be transported either mechanically or pneumatically with nitrogen as a carrier to avoid any risk of explosion and ignition in the dust transport line and silo. The pressure equalisation with nitrogen during the dust discharge process minimizes the release of blast furnace gas. The discharge process is controlled by level measurements installed in each hopper.

The low pressure drop and higher top gas temperatures lead to very low operation costs. In addition with a dry-type TRT the benefit of higher energy output, without producing more $\mathrm{CO} 2$ of such an installation can be even increased, and makes the overall project very appealing for funding programs also for revamp projects.

\subsection{Scrubber}

As part of a rebuild project of RNIL Vizag BF\#1, the gas-cleaning system design was developed to make the most of existing equipment and vessels, and thereby reduce capital expenditure. This practice was first established as a strategy for Primetals during a series of gas-cleaning projects carried out in the United States in the 1990s. The gas-cleaning system design for Vizag utilizes a three-cone arrangement in conjunction with a packed bed demister for water-droplet removal. This combination of equipment in a single vessel optimizes space and saves money. The successful and proven cone design using a duplex stainless steel material for both male and female elements forms the core of the facility.

This design is arranged to function with an existing energy recovery turbine. Matching the capacity of the newly relined furnace with the new scrubber against the turbine is a key activity. In the final design proposal energy recovery is maximized with all of the necessary back-up options provided in case of maintenance downtime. In this particular case, a septum valve is provided for the case that the turbine is not in operation. At all times, however, clean gas content is assured and can be achieved in order to meet the needs of the rest of the works.

The project for the rebuild of JSW BF\#3 proved also to be a turning point in the development of gas-cleaning systems for Primetals. The new cyclone and wetscrubber design is now part of the company's blast furnace solution portfolio.

The triple annular-gap cone scrubber uses three external cones for the most efficient gas cleaning in terms of dust content for the minimum pressure drop of the blast furnace gas. An $11 \mathrm{MW}$ recovery turbine installed downstream of the gas-cleaning plant is utilized to recover the pressure energy of the clean gas. A revolutionary new design wherein the scrubber cone elements are located outside the main vessel was installed. This solution enables a quicker and easier exchange during furnace outages (Fig. 4). 


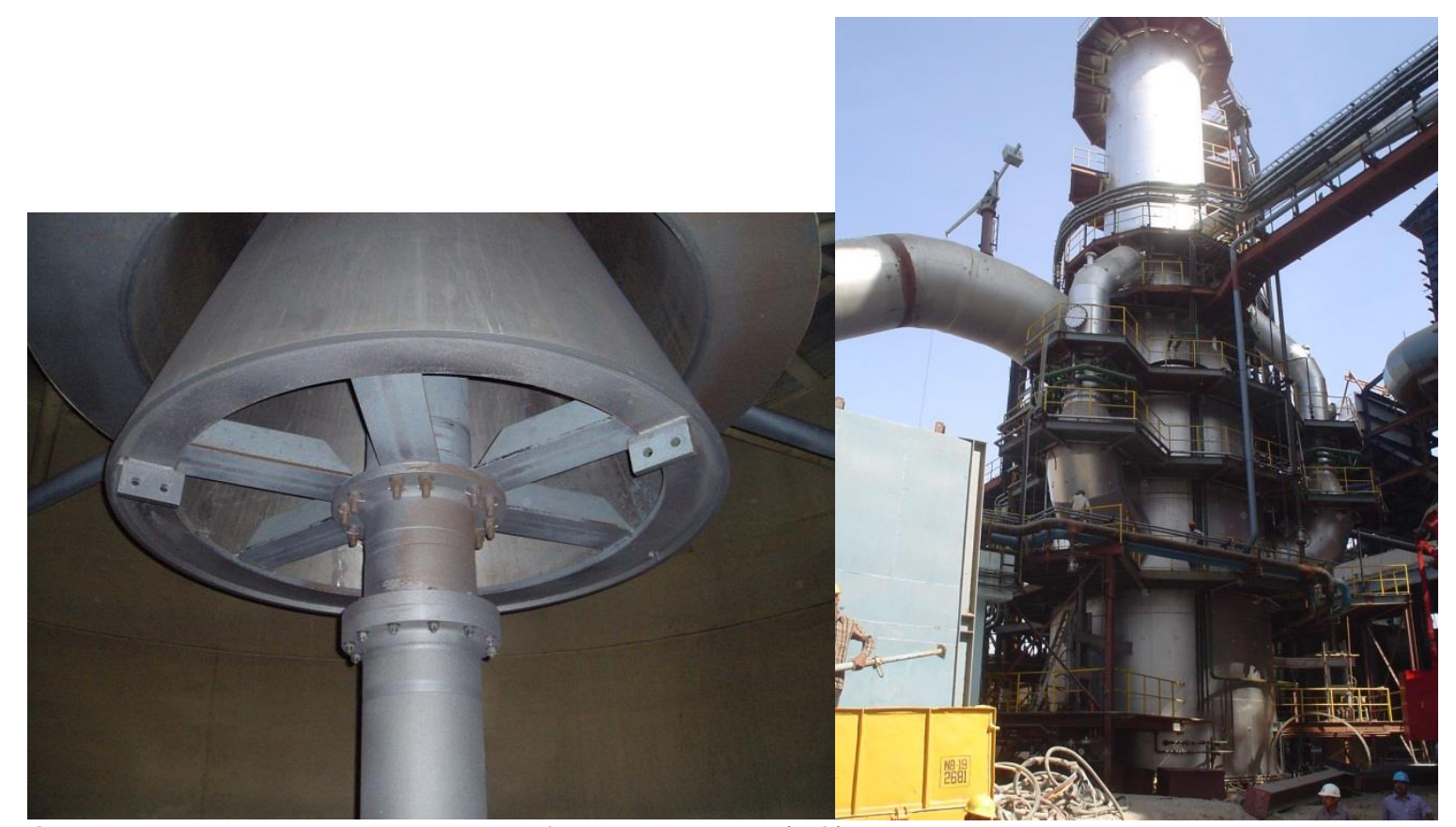

Figure 4. View on the cone element from the bottom (left) \& scrubber installation with external cone elements (right).

\subsection{SCR for Sinter plants}

The Selective Catalytic Reaction (SCR) Technology is a proven and state-of-the-art technology to reduce NOx emissions from stationary sources such as combustion plants, waste incineration plants, chemical plants and gas turbines, in most applications by reaction with ammonia $(\mathrm{NH} 3)$ or aqueous ammonium solution $(\mathrm{NH} 4 \mathrm{OH})$ on a catalytic surface in a reactor. At such plants, SCR typically is arranged upstream further gas treatment facilities, such as Electrostatic Precipitator (ESP) and Flue Gas Desulfurization (FGD), ensuring that the catalyst is arranged at a proper temperature zone for high efficient NOx reduction.

At sinter plants, the arrangement and design of the SCR DeNOx system is different: In order to remove both dust and SO2 emissions before entering the SCR DeNOx plant, NOx reduction typically is performed downstream ESP, fabric filter (FF) and/or FGD plants.The flue gas from sinter plant contains fine dust, which can contain different chemical compound that are known as catalyst poisons. Furthermore the dust can be sticky and can therefore easily accumulate onto the catalyst surface. Due to these special chemical characteristics of sinter plant waste gas, special attention has to be payed to the selection of catalyst and design of auxiliary equipment.

In general, the SCR DeNOx system is applicable for both existing sinter plants under modernization or completely new sinter plants installations. For existing sinter plants, the DeNOx can be installed downstream wet- or dry dedusting systems. However, the lower waste gas temperature downstream wet dedusting systems leads to higher effort for waste gas pre-heating and the saturated gas condition requires effective measures to prevent from corrosion in the respective low temperature areas (e.g. cold sides of gas-gas heater). [2] 


\subsection{Reactor design based on long-term SCR-DeNOx experience}

Having supplied 1,023 units of SCR plants and catalysts worldwide [3], especially for the power sector, Mitsubishi Hitachi Power Systems, LTD. (MHPS), as part of the Mitsubishi Heavy Industries, Ltd. and Primetals, is the ideal partner for the implementation of flue gas denitrification systems in iron- and steel making business. The excellent know-how of and experience of MHPS enables Primetals to supply the most efficient DeNOx system with an optimal design of the DeNOx reactor for a wide range of applications.

Using this experience, especially a compact reactor design with low pressure loss and considering sufficient retention time of the waste gas in the reactor can be realized. The catalyst packages itself are designed for minimized dust accumulation and erosion.

Together with the in-house know-how and experience in the field of waste gas cleaning solutions for sinter plants, Primetals is in the position to optimally design the DeNOx plant according to the individual waste gas characteristics and considering the sintering process to ensure highest plant reliability.

In order to economically achieve required NOx reduction rates, among others the following paraneters are considered:

Correlation between waste gas temperature at the inlet of catalyst, catalyst activity and resulting NOx reduction rate, under consideration of waste gas characteristics (i.e. SO3 concentration, etc.)

Correlation between waste gas velocity, resulting retention time and NOx reduction rate

Correlation between NOx reduction rate and raw gas NOx concentration

Correlation between NOx reduction rate and $\mathrm{NH} 3$ slip

Correlation between DeNOx plant operation hours and catalyst activity (deactivation curve)

Theoretically, $80 \%$ or more NOx reduction can be achieved with SCR technology at sinter plant, however this will mean installation of a SCR plant with high catalyst surface area and oversized auxiliary equipment. Therefore the DeNOx system in fact is individually designed to meet specific actual and future requirements on NOxemission limits. Furthermore, SCR could reduce dioxines concentration by catalyst reaction in sinter flue gas.

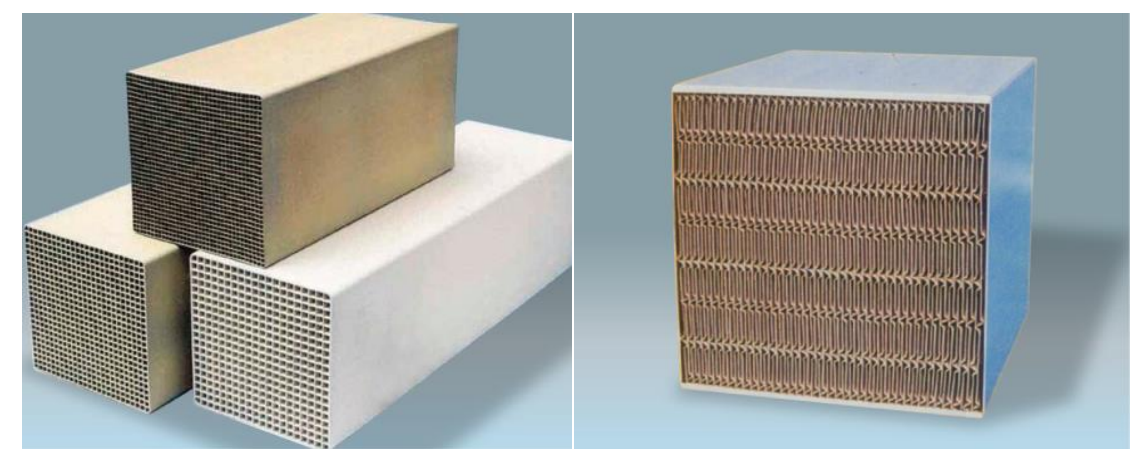

Figure 5. Typical DeNOx catalyst block types (left: honeycomb; right: plate) developed by MHPS [4] 


\subsection{Waste gas heating system for efficient SCR operation}

In the process design the boundary conditions for the SCR operation are determined and a concept of heat exchangers and heating system is elaborated to ensure a safe SCR operation with minimum pressure loss and external energy sources.

A rotor-type or plate-type, gas-gas heat exchanger (GGH) is installed to achieve highest thermal process efficiency. The heat exchanger transfers the bulk of thermal energy of the cleaned hot gas downstream the catalyst to the raw cold gas upstream of the duct burner system. Due to the special characteristics of sinter plant waste gas, special focus is set on the heating elements. Beside high thermal efficiency and low pressure loss, especially high corrosion resistance as well as low fouling affinity and good cleaning ability are key requirements. The rotary heat exchanger (Ljungström-type) is equipped with an efficient, advanced sealing system that minimizes the loss of heat transfer by minimizing bypass leakages. Manual adjustable sealing systems enable the setting of the seals during plant operation and ensure maximized plant performance. For profoundly cleaning, a high efficient soot blower system is part of the $\mathrm{GGH}$, operated either with pressurized air or superheated steam to prevent the heat exchanger packages from dust built-ups.

To increase and optimize waste gas temperature prior to entering the DeNOx reactor, in most cases a duct burner system is installed. For homogeneous input of thermal energy into the gas duct grid burners are applied that can be operated with Coke Oven Gas (COG) or Natural Gas (NG). Alternative heating concepts by using the waste heat from the sinter cooler from any other source by the means of steam or thermal oil heat exchangers are technically possible and can be investigated for every plant individually. Concepts which use the caloric value of the sinter off-gas itself to compensate the heating loss the GGH are also feasible.

\subsection{High-end gas cleaning solution for sinter and coke oven plants: MEROS and SCR DeNOx}

With the MEROS technology standing for Maximized Emission Reduction of Sintering, Primetals can offer the full package of efficient and state-of-the-art sinter waste gas cleaning technologies. In the MEROS process [5], with a series of successive treatment steps the dust, sulfuric oxides and harmful metallic and organic components present in the sinter waste gas are removed to levels previously unattained with conventional gas-treatment techniques. The MEROS system is easily expandable with the DeNOx system as the highly efficient MEROS gas cleaning plant ensures best available gas characteristics for subsequent, reliable and efficient NOx-reduction. These advanced gas cleaning systems in combination are now successfully in operation at the sinter plant of voestalpine Stahl, Linz/Austria as the world's first combined MEROS / DeNOx industrial plant since 2012, achieving highest removal efficiencies for fine dust, heavy metals, acid gases, dioxin and other VOC's, SOx and NOx.Figure 6. Basic scheme of SCR-DeNOx installed downstream MEROS at sinter plant shows a typical process scheme of the DeNOx system installed downstream the MEROS plant, achieving highest reduction of emissions from waste gas at sinter plants.

Advantages of the SCR DeNOx technology:

Highest removal efficiency for NOx (up to $90 \%$ );

Minimized ammonia consumption due to stable and optimized gas flow distribution; 
Optimal SCR reaction temperature by duct burner system operated with COG or NG; Coupling with innovative waste heat recovery solutions;

Lowest consumption of heating gas due to optimized heat exchanger design;

Efficient dust removal systems to minimize dust deposition on catalyst- and heat exchanger surfaces;

Plant design based on detailed knowledge of sinter off gas and dust behaviour;

Proper selection of catalyst for minimized clogging and long catalyst life-time.

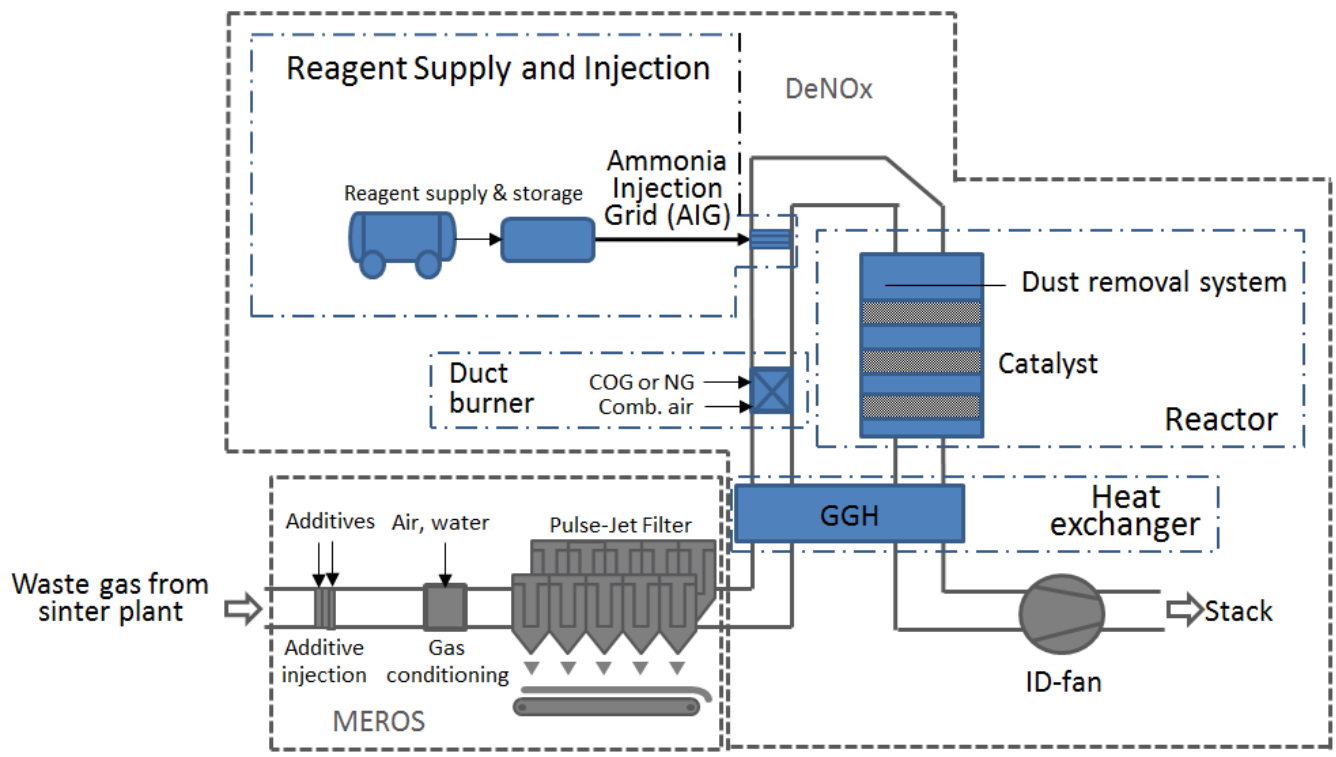

Figure 6. Basic scheme of SCR-DeNOx installed downstream MEROS at sinter plant

\section{CONCLUSION}

The paper gives an overview on the latest developments on gas cleaning technologies for ironmaking. Primetals and its partners offer safe and well proven solutions for the gas cleaning with an ample product portfolio and the possibility to meet with flexibility any customer's requirements in various plants of the ironmaking industry with minimal operation costs and highest availability.

The optimized dry and wet gas cleaning plants for the blast furnace offer the best opportunities to optimize the energy output and therefore reducing the carbon footprint and furthermore minimizing the impact of the gas cleaning plant on the product cost.

The strong partnership between the two companies Primetals and MHPS who have the focus on the gas cleaning of sinter plants and are providing deep process knowhow with invaluable knowledge in the gas cleaning technology to ensure a cleaner future.

\section{REFERENCES}

1 Lanzerstorfer C., Xu Q.: New Developments in Top Gas Cleaning of Blast

2 Furnaces: a Review; Berg- und Hüttenmännische Monatshefte, 159 Jg. (2014)

3 Remus R., Aguado Monsonet M. A., et.al.: Best Available Techniques (BAT) Reference Document for the Iron And Steel Production; (2013)

4 Mitsubishi Hitachi Power Systems: Air Quality Control System SCR/ESP/FGD (2015)

$5 \quad$ Mitsubishi Heavy Industries Technical Review Vol. 52 No.2 (2015) 
6 Fleischanderl A., Neuhold R., Plattner T.: MEROS® Sinter Off-gas Cleaning- Meeting Future Environmental Demands Now!; AIS Tech Conference, Indianapolis (2007) 